
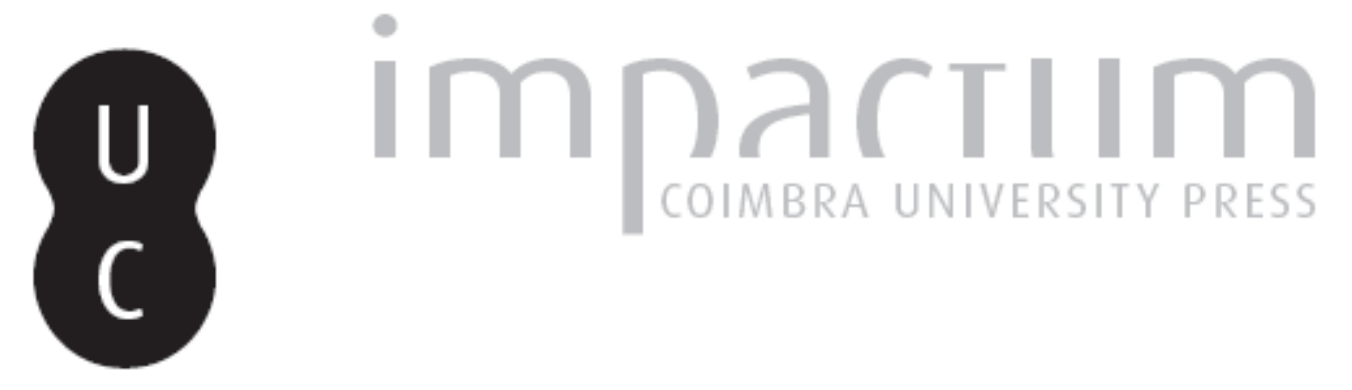

\title{
Arte comprometida: uma reavaliação
}

Autor(es): $\quad$ Nunes, Margarida

Publicado por: Imprensa da Universidade de Coimbra

URL persistente:

URI:http://hdl.handle.net/10316.2/35511

DOI:

DOI:http://dx.doi.org/10.14195/0870-4112_11_13

Accessed : $\quad$ 26-Apr-2023 02:19:02

A navegação consulta e descarregamento dos títulos inseridos nas Bibliotecas Digitais UC Digitalis, UC Pombalina e UC Impactum, pressupõem a aceitação plena e sem reservas dos Termos e Condições de Uso destas Bibliotecas Digitais, disponíveis em https://digitalis.uc.pt/pt-pt/termos.

Conforme exposto nos referidos Termos e Condições de Uso, o descarregamento de títulos de acesso restrito requer uma licença válida de autorização devendo o utilizador aceder ao(s) documento(s) a partir de um endereço de IP da instituição detentora da supramencionada licença.

Ao utilizador é apenas permitido o descarregamento para uso pessoal, pelo que o emprego do(s) título(s) descarregado(s) para outro fim, designadamente comercial, carece de autorização do respetivo autor ou editor da obra.

Na medida em que todas as obras da UC Digitalis se encontram protegidas pelo Código do Direito de Autor e Direitos Conexos e demais legislação aplicável, toda a cópia, parcial ou total, deste documento, nos casos em que é legalmente admitida, deverá conter ou fazer-se acompanhar por este aviso.

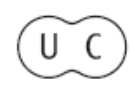




\section{ESTÉTICA E POLÍTICA}

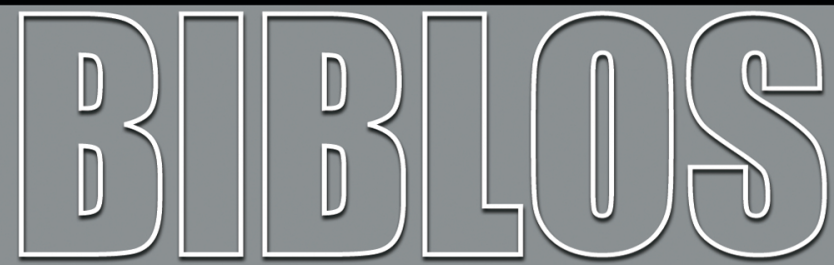

REVISTA DA FACULDADE DE LETRAS UNIVERSIDADE DE COIMBRA 
Biblos, n. s. XI (2013) 335-340

DOI: http://dx.doi.org/10.14195/0870-4112_11_13

Margarida Nunes

\title{
ARTE COMPROMETIDA - UMA REAVALIAÇÃO
}

\section{Resumo}

A criação artística ultrapassará sempre a mera experiência sensorial, mesmo que, aparentemente, recuse qualquer inscrição no seu tempo histórico e político. Entre o autor e a obra interpõe-se um conjunto de valores morais, políticos e ideológicos, não sendo defensável a existência de neutralidade no discurso artístico. Ainda que com referência à contemporaneidade, a arte surge-nos neste trabalho como criação comprometida, por oposição ao conceito de experiência sensorial pura.

Palavras-chave: arte engajada, comprometimento, neutralidade, política e sociedade.

\begin{abstract}
The artistic creation goes always beyond the immediate sensory experience, even if apparently refusing any form of participation in its historical and political time. Between the author and the work mediate moral, political and ideological values and it is not defensible an unpolluted neutrality of the artistic discourse. Although focused on contemporaneity, in this paper art emerges to us as engaged creation, thus differing from the concept of a pure sensory experience.
\end{abstract}

Keywords: engaged art, engagement, neutrality, politics and society. 
Diversas poderão ser as abordagens sobre as relações entre a estética e a política, reivindicando algumas delas a existência de um discurso estético autónomo. Dificilmente se poderá ter qualquer tipo de distanciamento quando se pondera esta temática do ponto de vista do criativo, assumindo-se assim claramente, e decorrente deste facto, uma visão pessoal, parcial e comprometida, sem contudo prescindir de uma reflexão mais abrangente sobre esta problemática.

Muito se tem produzido acerca da chamada "arte engagée", reputando-a muitas vezes de politizada e menos criativa, tornando-a suspeita de trair a causa da arte e de reduzir as obras à expressão de uma tese ${ }^{1}$. Se é certo que o comprometimento de muitos artistas com os regimes políticos e institucionais vigentes à época, resultou a mais das vezes numa arte de propaganda, assalariada de uma elite política e eticamente identificada ${ }^{2}$, não é menos verdadeiro, de outro modo, que muitos dos nomes maiores da criação artística foram assumidamente pioneiros, seguidores e importantes veículos de transmissão de novos conceitos políticos e sociais, contribuindo para uma discussão livre e visando a transformação do mundo ${ }^{3}$.

Se a chamada arte engajada é suspeita de trair a causa da própria arte, não é menos verdade que ao longo da história, as escolhas estéticas sempre decorreram, quer por adesão, quer por recusa, de um conjunto de valores políticos - dominantes, quando falamos da denominada "arte do regime", ou transgressores, nos exemplos da "arte de contestação" ou "libertária".

Começa pois, a delinear-se aqui a existência de duas facetas de uma mesma atitude de comprometimento, em que os valores pré-existentes

\footnotetext{
${ }^{1}$ Evelyle Pieiller.
}

${ }^{2}$ Referimo-nos ao colaboracionismo com o regime anti-semita alemão e fascismo italiano, de que foram claros apoiantes Celine, Ezra Pound e Leni Riefensthl, bem como Eduardo Munch e Mies Van Der Rohe - os dois últimos, pelo menos, numa primeira fase, passando mais tarde a assumir uma atitude mais crítica. A este respeito, refira-se ainda as correntes associadas ao regime comunista soviético, bem como o neorealismo muito presente na arte em Portugal.

${ }^{3}$ BERTOLD BRECHT, arquétipo do chamado artista engajado, foi indubitavelmente um grande teórico e prático da denominada "arte política". Poder-se-á ainda referir, contemporaneamente, a onda revolucionária da denominada "Primavera Árabe" e alguns grupos de artistas fortemente críticos do capitalismo, nomeadamente em Espanha. 
no artista surgem declaradamente na sua obra. Admitindo porém que a separação entre o artista e a obra é questionada a partir do séc. XIX, não se afigura defensável a autonomia plena da criação artística. Esta emerge sempre de um autor, carregando no seu processo conceptual e criativo todas as suas circunstâncias e valores. Traduzirá sempre um comprometimento com um conjunto de valores ético-políticos que mais não são do que o resultado do seu percurso pessoal e social e, eventualmente, das suas escolhas ideológicas e políticas. Assim sendo, a escolha entre a existência de um compromisso ou a ideia de arte como descomprometida, será sempre uma questão decorrente de muitas outras que lhe pré-existem, como aquelas que se debruçam sobre a natureza do homem e a sua formação como ser individual, social e político.

Remontando às vanguardas Modernistas, onde a politização da arte denota um carácter óbvio, claramente conotado com movimentos mais ou menos fechados, identificados mesmo por manifestos, o discurso artístico é claramente comprometido, e este facto é apreendido pelo observador numa primeira análise. Mas será que o que hoje denominamos de arte contemporânea, conseguiu ultrapassar e remeter para o passado a questão da chamada "arte mensageira", com conteúdo social e político objectivo? Poderá a arte reivindicar o direito a um discurso próprio e autónomo? Certo é que a contemporaneidade elevou ao estatuto de arte meros objectos do quotidiano, expurgando-a aparentemente de qualquer conteúdo social e ideológico. Também os discursos catastrofistas que anunciam o fim da arte poderão voltar a colocar esta questão, tornando defensável a existência de um discurso estético autónomo.

Não se corrobora a existência deste discurso artístico neutral e esteticamente puro. Desde a escolha do conceito até à definição da estética final apresentada, não consubstancia uma atitude de distanciamento ou mesmo de despersonalização. Os discursos catastrofistas já referidos nascem claramente de uma atitude de contestação, recusando seguir o "já feito" e inscrevem-se num movimento de negação e anunciação do fim, a que não serão alheios os conceitos e os valores do artista aderente.

Observando ainda hoje, algumas criações aparentemente "anódinas" e "neutrais", parecendo meras reproduções de uma realidade natural e estática, pareceria lógico a possibilidade de admitir a tese da obra por si mesma e um consequente descomprometimento. Pois trata-se, defendemos, de um duplo engano. Se este tipo de criação artística, materializada na obra final, saída das mãos e da concepção de um autor, 
mais não serve do que a reprodução fiel e acrítica de uma realidade, natural ou social, a classificação destes mesmos trabalhos como arte, poderá arrepiar todo o conceito em si mesmo. Arte implica criação, singularidade, linguagem e conceito, não pode satisfazer-se com meros conceitos de reprodução e técnica. Se assim é, duvidoso se torna admitir tais trabalhos como obras de criação artística, cabendo-lhe um lugar no campo das técnicas e, a mais das vezes, na perfeição das cópias este é o primeiro engano!

Mas existe um segundo, para análise do qual, se propõe o seguinte exercício, que implica em si mesmo, uma concessão e até admissibilidade da negação do primeiro argumento. Admitindo-se ainda assim, por hipótese, que tais trabalhos técnicos a que acima nos referimos poderão ter estatuto de arte, o simples facto de reproduzirem uma realidade estática e acrítica, revela, em si mesmo, uma atitude igualmente passiva e neutral por parte dos seus autores. Assim sendo, também eles são comprometidos/engajados com uma visão passiva, silenciadora e conservadora, relativamente à arte e ao mundo. Muitas dessas obras, representam a beleza em si mesma, enquanto único valor, tentando subornar um gosto obsoleto aceite pelas classes endinheiradas e com duvidosa formação estética, são em si mesmas representativas de uma atitude silenciosa e cómoda, de que resulta a procura do unanimismo e da consequente "carreira" comercialmente compensadora e rentável. O artista supostamente desengajado é, consciente ou inconcientemente, inteiramente comprometido com a recusa da inovação e da crítica, negando-se a assumir qualquer atitude de singularidade e risco, tornando-se veículo de transmissão e muitas vezes "bandeira" do regime e das instituições vigentes - são os chamados artistas do regime, uns por acção (transmitindo declaradamente os conceitos ético-políticos dominantes), outros por omissão (demitindo-se de qualquer atitude incómoda e de confronto, tornando-se fazedores de obras decorativas e comercialmente transacionáveis).

Finalmente, acreditamos ainda que tão pouco a questão levantada pela existência da heteronímia ${ }^{4}$ poderá fazer-nos vacilar na constru-

\footnotetext{
${ }^{4}$ Questão sobre a qual se debruçaram alguns autores, referindo-se exemplificativamente o nome de Allan Kaprow, assemblagista e pioneiro do conceito de performance de "ambiente" e de "happening" nos finais da década de 50 e década de 60 .
} 
ção argumentativa que acima se defendeu. A realidade da heteronímia, levantará certamente a questão da separação entre o autor e a sua obra, a que também já aludimos, dado que estaremos perante uma personalidade fictícia e distinta do autor - estaremos?. Também aqui dois argumentos se fundem, embora numa abordagem apriorística, possam parecer distanciar-se. A obra, como resultado de um heterónimo poderá, aparentemente, não ter qualquer manifestação do comprometimento do autor, mas tê-lo-á sempre com a personalidade por este criada e emprestada ao heterónimo. Se assim não fosse, porque escolheria o autor este ou aquele heterónimo e não quaisquer outros? Porque teria necessidade de criar uma personalidade distinta da sua para dar corpo a esta ou àquela obra? A heteronímia não nos abala a tese que vimos defendendo. Ela é também um processo conceptual e criativo da responsabilidade do autor primeiro. Resulta pois, ou de uma escolha consciente e determinada, engajada na sua personalidade e consequência do que carrega como estruturante, ou, por antítese, da construção de uma nova personalidade emergente da necessidade, consciente ou não, da recusa e afastamento de toda a carga emocional, ética e social que serviu de base à sua construção como homem individual e ser social.

Crê-se pois, sendo o Homem um ser político, não cabe pensar a negação dessa condição em qualquer faceta da sua existência. A condição do criativo/artista como ser social e político, decorre da sua condição humana e manifesta-se mesmo quando este se inscreve, aparentemente, numa linguagem neutra e acrítica. Terá sempre de se inscrever numa determinada visão do mundo e da existência, estando por isso condenado a uma inserção social e política - quer o artista o faça por acção, quer por omissão. Nada é mais falacioso do que pensar a neutralidade em qualquer acto da existência, por maioria da razão, também no acto criativo. A neutralidade é uma invenção pura, o acto de declarar-se neutro e descomprometido, é de per si, uma adesão ao status quo existente. Advogando a neutralidade, o artista inscreve-se numa recusa de mudança, negando qualquer linguagem transformadora e conformando-se com a realidade. A neutralidade é também um claro comprometimento e traduz uma atitude engajada com a estética dominante e com o status quo de cada época histórica.

Perante linguagens assumidas e consubstanciadas em declarações de interesses (tal como nas correntes artísticas denunciadas pelos seus próprios Manifestos), exerce-se o contraditório e estimula-se a discus- 
são sobre o discurso artístico. Mais difícil se torna exercê-lo perante linguagens ambíguas ou silenciosas que subtilmente se apresentam e entranham no observador.

A ideia de engajamento está sempre presente, por tese ou por antítese, resulta sempre de uma atitude mais ou menos consciente e está na base de toda a criação artística, nela deixando marcas de leitura mais ou menos óbvia, de uma visão da arte e do mundo que sendo necessariamente individual, será, por isso mesmo, comprometida. A suposta arte descomprometida, reivindicando para si uma experiência sensorial pura, apenas aparenta um discurso estético livre e autónomo. Não deixa de traduzir sempre um posicionamento identificável, ainda que por demissão ou omissão de qualquer conceito e estética transformadores. 